\title{
Modeling the Effects of Sewer Mining on Odour and Corrosion in Sewer Systems
}

\author{
N. Marleni ${ }^{a}$, S. Gray ${ }^{\text {b }}$, A. Sharma ${ }^{c}$, S. Burn $^{c}$ and N. Muttil ${ }^{\text {a }}$ \\ ${ }^{a}$ College of Engineering and Science, Victoria University, Melbourne \\ ${ }^{b}$ Institute of Sustainability and Innovation (ISI), Victoria University, Melbourne \\ ${ }^{c}$ Commonwealth of Scientific, Industrial and Research Organization (CSIRO) \\ Email: nepi.ninyoman@live.vu.edu.au
}

\begin{abstract}
Increasing demand has led to shortage of potable water in many countries. The use of alternative water sources is one of the solutions undertaken to overcome this issue. Alternative water sources can be derived from either collected rainwater, treated greywater or treated wastewater. Sewer Mining is known as an efficient technology which can reduce the cost of wastewater infrastructure required to transport wastewater because the Sewer Mining facility is usually installed close to the site that is using the treated wastewater. The treated water from Sewer Mining has been used as one of the sources of alternative water, particularly to supply water for public open spaces, garden irrigation and toilet flushing. It is conducted by extracting the sewage from sewer pipes and most of the times, disposing the sludge back to sewer pipes. The sewage extraction and sludge disposal back to sewer network is suspected to trigger sewer problems such as blockages. Several applications of Sewer Mining facility have proved to contribute to the increase of blockages in sewer pipes. Furthermore, the changes in the sewage composition after the sewage extraction and sludge disposal location lead to alteration of the sewage biochemical transformation processes, which finally were suspected to change the state of hydrogen sulphide build up. Increase of hydrogen sulphide in sewage and in the sewer atmosphere could also contribute to the problem of odour and corrosion in sewers.
\end{abstract}

This study attempts to model the impact of Sewer Mining on odour and corrosion in sewer systems. A residential area in northern Melbourne was used as a study area. In this study, four Sewer Mining scenarios were considered, consisting of Base Case (BC), Sewer Mining 1 (SM1), Sewer Mining 2 (SM2) and Sewer Mining 3 (SM3). The scenarios were configured based on the volume of sewage extraction. Base Case is the scenario representing the existing condition of water and wastewater use in the study area and there was no Sewer Mining facility in the area. Sewer Mining 1, 2 and 3 represent the scenarios when the Sewer Mining is undertaken and the sewage extraction was adjusted to supply $25 \%, 50 \%$ and $70 \%$ of the households in the study area. The location of sewage extraction and sludge disposal was fixed at the middle of main sewer pipe network and was not changed for each scenario. The treated water from the Sewer Mining facility was supplied as water for toilet flushing.

Two modeling tools were used for this analysis, the first was an urban wastewater generation model and the second was a sewage transformation (and generation of hydrogen sulphide) model. The output of the first model, namely wastewater flow discharge and contaminant concentration were fed to the second modeling tool. Wastewater generation from the households was simulated in the first modeling tool while Sewer Mining practice was modeled in the second modeling tool. Its impact was analyzed in the sewer pipes downstream of the Sewer Mining facility. The analysis results were obtained by comparing the result from Sewer Mining scenarios 1, 2 and 3 with the Base Case. The difference in total sewer flow, hydrogen sulphide gas production, corrosion rate and the pipe lifetime were the analysis parameters that are discussed in this paper.

The results showed that Sewer Mining led to reduction in hydrogen sulphide concentration immediately after the sewage extraction point, but further downstream, the hydrogen sulphide concentration was extremely high. The hydrogen sulphide concentration at the outlet of sewer pipes network for SM1, SM2 and SM3 scenarios had increased up to three, five and eight times respectively, when compared to the hydrogen sulphide concentration in the Base Case. Increase of hydrogen sulphide concentration consequently lead to increase in odour occurrence and corrosion rate which eventually reduce the sewer pipe lifetime. The pipe lifetime at the outlet of sewer network reduced by 204 years, 262 years and 293 years after implementing the scenarios of SM1, SM2 and SM3, respectively. The distance where the extremely high hydrogen sulphide generation occurred was very much determined by the volume of extracted sewage and the location of extracted sewage and sludge disposal.

Keywords: $\quad$ Sewer Mining, Sewer systems, Odour, Corrosion, Hydrogen Sulphide 


\section{INTRODUCTION}

Due to global climate change and rapid population growth, there is a worldwide effort to reduce water demand. Substitution of water for non-potable uses with Alternative Water Source such as rainwater or treated blackwater and greywater were more encouraged to reduce water demand. Latest wastewater recycling invention called Sewer Mining is increasingly in demand recently due to its high efficiency treatment as well as less space required to install this treatment. Sewer Mining does not use conventional wastewater treatment plants, but typically a compact, sometimes portable advanced treatment plant. Sewer mining include where wastewater is extracted from an existing sewer and then and reused. Most of the existing Sewer Mining operations use their reclaimed water for public space irrigation and toilet flushing (Hadzihalilovic 2009; McGhie et al. 2009; Sydney Water 2006). Despite its use for public area, in some cases, the treated water from sewer mining was also used to supply non-potable domestic water demand. Households in residential areas usually use reclaimed water for toilet flushing and laundry water. The uses of treated water from sewer mining to supply residential water are predicted to increase in the years to come.

To avoid a problem of sewer sedimentation, Sewer Mining is only allowed to be installed in locations where there is sufficient wastewater flows in sewer networks to flush out any solids that may have been deposited during low flow periods. The flow is deemed sufficient when minimum sewer operational flow is calculated by considering diurnal flow pattern and other activities which extract sewage upstream or downstream of the proposed Sewer Mining extraction point. Many Sewer Mining activities allow the treatment residuals (e.g. treatment sludge) to be discharged back to the sewer as long as it does not substantially increase the load in the sewer (Sydney Water 2008). According to Sydney Water (2008), the residual discharge of Sewer Mining is more likely to contain grit, more concentrated wastewater and some additives from treatment such as iron, aluminium and sulphate. Problems will arise from a Sewer Mining operation if the treatment residuals (treatment sludge which consist of suspended solid, grit and chemicals) are discharged back to the sewerage networks without considering the minimum sewer flow. Furthermore, the setup of regulations was intended only to overcome the solid problem in sewerage networks, while neglecting organic and chemical problems that can lead to sewer odour and corrosion (Marleni et al. 2012). While the sewer mining impact on sediment deposition has been recognized by many stakeholders, the impact on other sewer problems such as sewer odour and corrosion have not been identified yet. Lower sewer flow velocity and increase of contaminant load due to treatment sludge disposal to sewer pipe are estimated to increase activity of biochemical transformation.

Hydrogen sulphide gas is product of biochemical transformation process that responsible for causing odour and corrosion. Hydrogen sulphide gas is a dissolved sulphide that was released to the sewer atmosphere under certain sewer circumstances. Dissolved sulphide can be released to the sewer atmosphere if there is high flow turbulence, high wastewater $\mathrm{pH}$ and temperature (Jensen et al. 2009). Odour caused by hydrogen sulphide gas can endanger sewer workers because the fumes cause illness if the concentration is more than $10 \mathrm{ppm}$ and can be lethal at concentration of $500 \mathrm{ppm}$ (Hvitved-Jacobsen \& Vollertsen 2001). The cost for corrosion rehabilitation or maintenance is high. In Los Angeles county, for example, rehabilitation of $10 \%$ of the sewer network cost approximately $\$ 420$ million and in Belgium, the maintenance cost for preventing corrosion amounts to $\$ 6$ million per year (Zhang et al. 2008). This paper attempts to study the impact of sewer mining that installed in residential area on sewer odour and corrosion.

\section{STUDY AREA}

The case study site chosen was in the Yarra Valley Water service area. The case study site was selected based on consideration of the requirements for the residential area which mostly consists of detached houses and occupied by family size household (more than 1 person per house). The chosen residential area is located around the Glenroy sewer subcatchment which lay within Moreland City Council in northern Melbourne as can be seen in Figure 1. The total households in this area were estimated around 3750 households. According to Roberts (2005), the household size is around 2.55 person per household. In the study area of 425 $\mathrm{Ha}$, a typical residential size block was assumed to be in the range of $125-790 \mathrm{~m}^{2}$. In an earlier investigation of the Pascoe Vale catchment, hydrogen sulphide related

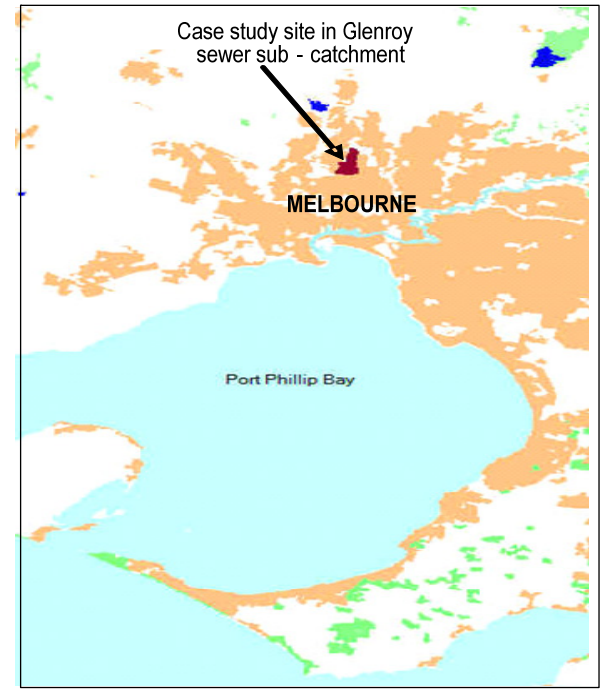

Figure 1. Case Study Site - Glenroy Sewer Subcatchment 
degradation of the sewer pipes caused sewer collapses in 1999 and 2004. The investigation found that the slope of upstream stretch in the Glenroy branch varied between being too flat to being too steep, developing conditions for hydrogen sulphide build up and release. From CCTV examination by water utility, it was also found that the structural grading of a total of $1283 \mathrm{~m}$ sewer pipe in this area was classified as moderate to worse deterioration.

The existing alternative water sources of rainwater and treated greywater have been used in few houses in this area. Around $30 \%$ of the residential households in this area haveainwater tank and $3 \%$ of the households have greywater recycling facilities. However, the usage of collected rainwater is mostly to supply irrigation water (gardening) and only 3\% used the collected rainwater for toilet/laundry purpose. There is no information available to specify the usage of treated greywater from greywater recycling facility.

\section{METHODS}

\subsection{Modeling Tool and Framework}

Two modeling tools are needed to predict both sewer flow and hydrogen sulphide production in the sewer system. The first tool is used to estimate the wastewater flow and contaminant load from urban residential catchment from every Sewer Mining scenarios and the second tool estimates the production of hydrogen sulphide. Urban Volume and Quality (UVQ) model was selected to simulate the urban wastewater generation and Wastewater Aerobic/Anaerobic Transformation in Sewer (WATS) model was selected to simulate the sewer wastewater quantity and quality as well as hydrogen sulphide production. The outputs of UVQ simulation were converted to wastewater flow and contaminant concentration for every discharge point (nodes). The converted outputs from UVQ are then used as inputs for WATS model. Detail of input and output for each models are listed in Table 1.

Table 1. Model Data Requirement

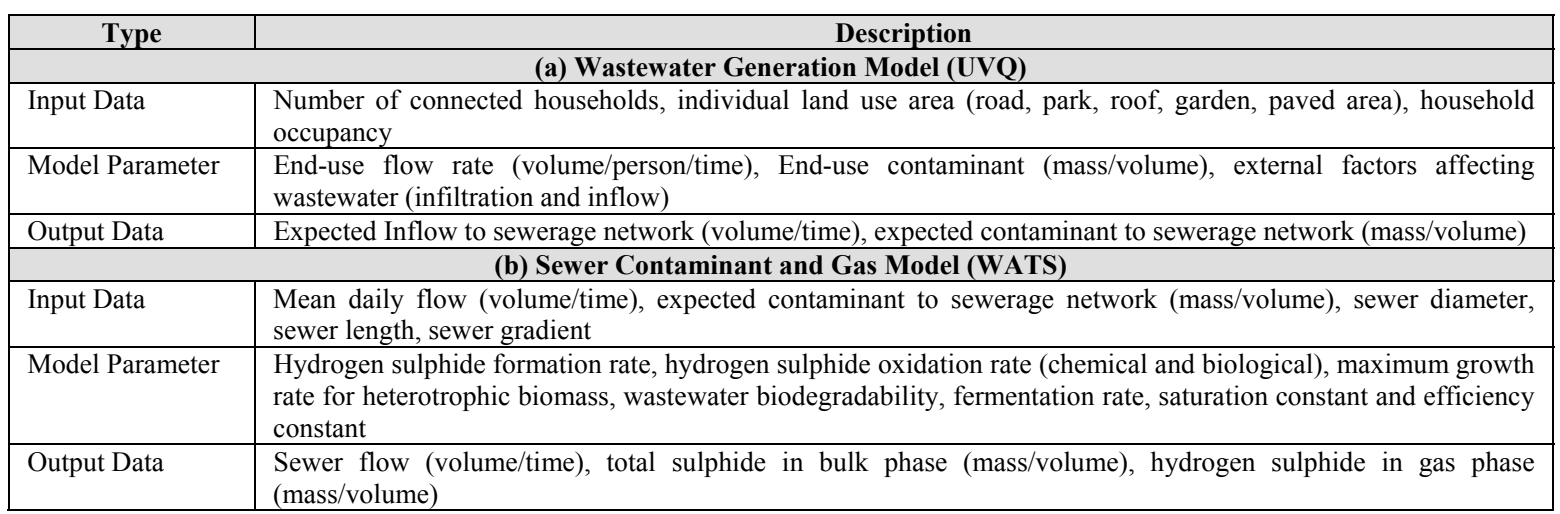

\subsection{Selection of Sewer Mining Location and Development of Sewer Mining Scenarios}

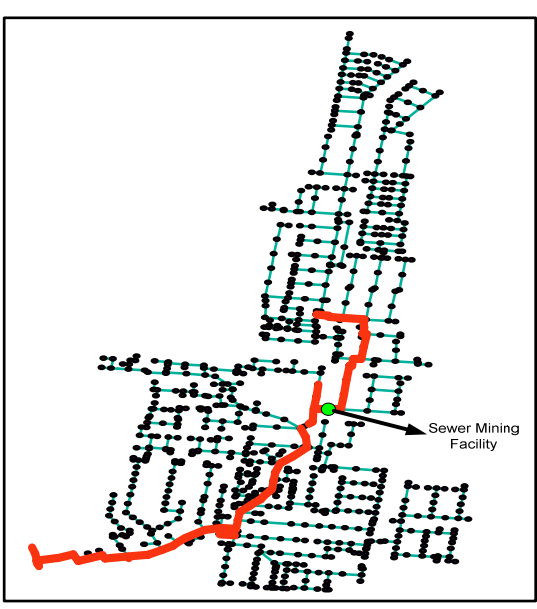

Figure 2. Glenroy Sewer Network \& Proposed Sewer Mining Location
The extracted sewage for Sewer Mining plant was taken from the $300 \mathrm{~mm}$ diameter Glenroy sewer branch. The extraction point as can be seen in Figure 2 was selected based on following four main reasons, three of which are based on the considerations from Hadzihalilovic (2009)'s study. The reasons are as below:

1. It is located near the households that will be supplied by treated water from Sewer Mining facility.

2. It is located in a residential catchment, since the wastewater quality from residential catchment is fairly uniform quality, hence the treatment process will be relatively simple and reliable.

3. The volume of sewage from this location is expected to increase in the future.

4. It is located in the middle part of major sewer pipes, allowing some downstream pipes to be impacted due to the Sewer Mining facility. 
Table 2. Sewer Mining (SM) Scenarios

\begin{tabular}{|c|c|c|}
\hline Scenario & \multicolumn{2}{|c|}{ Practices } \\
\hline \multirow{3}{*}{$\begin{array}{l}\text { Applied to } \\
\text { all SM } \\
\text { Scenarios }\end{array}$} & Rainwater Tank & $30 \%$ \\
\hline & $\begin{array}{l}\text { Rainwater connect to } \\
\text { Toilet/Laundry }\end{array}$ & $3 \%$ \\
\hline & $\begin{array}{c}\text { Greywater Recycling } \\
\text { Storage }\end{array}$ & $3 \%$ \\
\hline Base Case & \multirow{4}{*}{$\begin{array}{c}\text { Volume of Extracted } \\
\text { Sewage }\end{array}$} & $0 \mathrm{~m}^{3} /$ day \\
\hline SM 1 & & $69 \mathrm{~m}^{3} /$ day \\
\hline SM 2 & & $153 \mathrm{~m}^{3} /$ day \\
\hline SM 3 & & $214 \mathrm{~m}^{3} /$ day \\
\hline
\end{tabular}

Sewer Mining scenarios include Base Case and three scenarios with different sewage extraction volume. Base Case represents current condition in study area where there is no sewer mining facility and all condition pictured in Section 2 (Study Area). The other Sewer Mining scenarios were set to supply $25 \% ; 50 \%$; and $70 \%$ of households in the study area. Table 2 describes the configuration of Sewer Mining scenarios. The maximum sewage extraction for Sewer Mining facility was only set to $70 \%$ because limited sewage volume in the location of extraction. The wastewater in extraction point could only supply maximum $75 \%$ of households in the study area. However, since there should be some sewage left to maintain minimum sewer flow $70 \%$ of households was selected to be the highest percentage supplied by Sewer Mining's treated water. The impact of Sewer Mining installation was predicted to occur downstream of the sewage extraction point.

\subsection{Sewer Mining Modeling}

In this study, Sewer Mining involves extracting raw sewage from an existing sewer and treating it at the cluster scale. The recycled water from the plant is used for toilet flushing. Any by products (e.g. sludge) were disposed back to the sewer main. Based on previous Sewer Mining studies, membrane bioreactors are the most common treatment method selected to treat wastewater from sewers (Hadzihalilovic 2009; McGhie et al. 2009). The removal efficiency of Membrane Reactor was taken from Tchobanoglous et al. (2003). The storage tank capacity of treated wastewater was set to $500 \mathrm{~m}^{3}$, and the initial capacity set to half of the total storage capacity. Since there were no individual modeling tool had the capability to model Sewer Mining from the locations of waste generation until the outlet of the sewer, therefore in this study, two modeling tools were used with some adjustments on the models. These adjustments were affecting the results; therefore cautions should be taken when interpreting the results of sewer mining modeling.

In the wastewater generation model (UVQ), the wastewater recycling plant, which is represented as the Sewer Mining facility, was assumed to be installed in every cluster and the storage tanks were adjusted until the toilet flushing water demand was fully supplied (100\% system reliability). Since every cluster has a different number of households, the assumption and adjustment made lead to the different size of the cluster storage tank for every cluster. However, since the variation in storage tank volume is not a focus of this study, it can be neglected. The calculation of total sewage extracted from sewer pipe to supply the toilet water demand for $25 \%, 50 \%$ and $70 \%$ of households in the study area was based on the difference in wastewater volume in the Base Case and Sewer Mining scenario. The contaminant load that discharges to the sewer pipe network was obtained from the summation of wastewater contaminants load in excess wastewater and sludge production. However, this scenario neglected the additional contaminant load originated from the treated water of Sewer Mining plant, which used to supply toilet flushing water. This arrangement might underestimate the total contaminant load discharged from a household, since the alternative water from the Sewer Mining plant would contain a higher contaminant load compared to that in potable water. Another adjustment was also implemented in the sewer pipe modeling tool (WATS). Since WATS did not provide any node that had the capability to treat and store wastewater extracted from the sewer pipe, two normal nodes were added to the network. The first additional node was intended to be a sewage receiving node, while the second node functioned as a sludge discharging node. By using this adjustment, the time lapse from sewage was extracted to sludge was produced was ignored. The modification assumes that the sludge was produced at the same time as sewage was extracted, which is not really correct in reality.

\section{RESULTS AND DISCUSSION}

\subsection{Sewer Flow}

Figure 3 depicts comparison of total sewer flow in Glenroy sewer. The increasing extracted sewage volume has shown further decreasing in wastewater flow. The total sewer flow in Base Case, SM1, SM2 and SM3 are $904 \mathrm{~m} 3 /$ day; $836 \mathrm{~m} 3 /$ day; $753 \mathrm{~m} 3 /$ day and $692 \mathrm{~m} 3 /$ day respectively. In SM1, the sewage extraction of 69 $\mathrm{m} 3 /$ day which can supply $25 \%$ households in study area has successfully decrease the wastewater flow 68 $\mathrm{m} 3 /$ day which is only $7 \%$ of total wastewater in study area. For SM2, the extraction of sewage of $153 \mathrm{~m} 3 /$ day (supply for $50 \%$ households in study area) consequently brought down the total wastewater volume as much 
as $151 \mathrm{~m}^{3} /$ day which equal to $17 \%$ of the total wastewater. SM3 extracts $214 \mathrm{~m}^{3} /$ day sewage that finally reduced the total wastewater by $211 \mathrm{~m}^{3} /$ day, this number is equal to $23 \%$ of total wastewater in study area. Though the reduction of total wastewater flow is not that high but it is important to note that impact on odour and corrosion through hydrogen sulphide generation does not only depend on the sewer flow. But it also depends on how much contaminant disposed back to sewer network.

Figure 4 shows the impact of sewer mining facility which is installed in the middle of sewer network. The sewer flow after the point of extraction was dropped depends on the volume of extraction. From this figure, it can be understand that the impact of sewer mining will occur after the point of extraction (downstream pipes) while the upstream pipes are relatively were not affected.

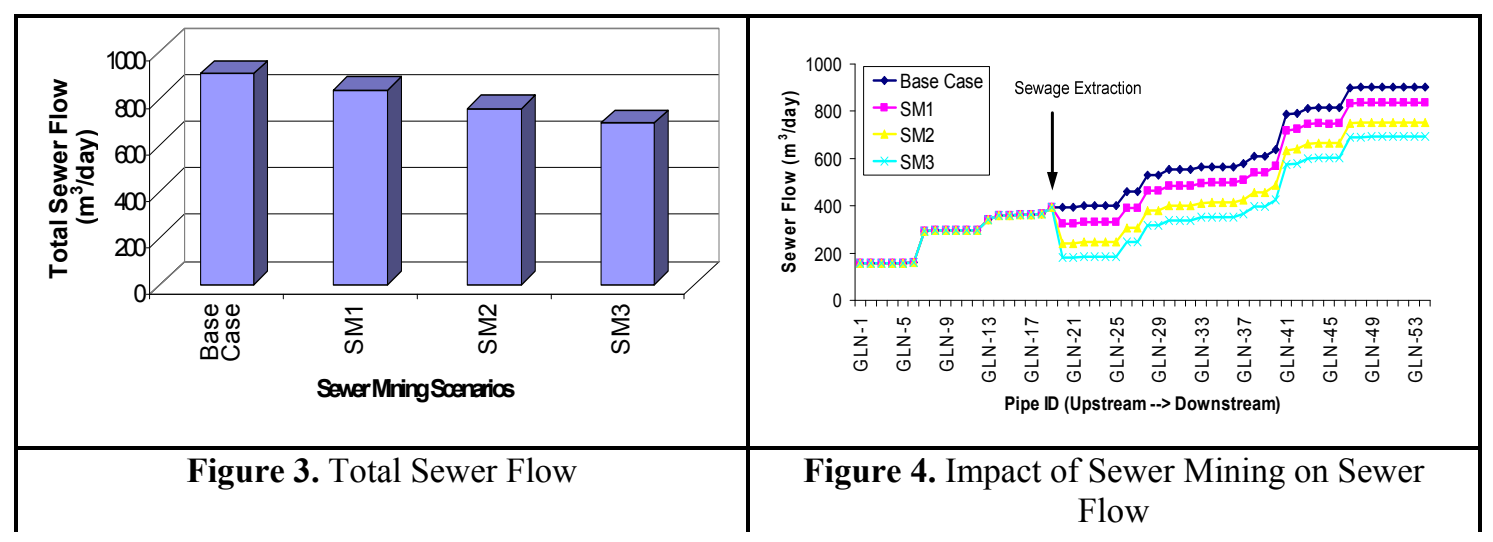

In existing sewer networks, sewer flow reduction may offer a benefit of excess flow capacity which can later be used to accommodate downstream population expansion, thereby eliminating the need for new construction. However, sewer flow reduction also gives consequence of low flow which relates to long residence time of sewage as well as low velocity. Long residence time lead to anaerobic condition that supports sulphide formation (Nielsen et al. 2008; Nielsen et al. 2005). Low flow velocity reduces the capability of sewers pipe's self cleansing; as a result, much sediment is left in the bottom of pipes.

\subsection{Odour}

A consequence of the presence of odorous sewer gas in sewer pipes is the potential danger, mostly to sewer workers, and in some cases, to the public near the odorous site. For hydrogen sulphide, the threshold value of detection is quite low $(0.002 \mathrm{ppm})$. At this concentration, it does not create any harmful effects (HvitvedJacobsen 2002). The odour will start to become a nuisance at concentrations of more than 0.5 ppm. Further, when the hydrogen sulphide gas concentration is above $10 \mathrm{ppm}$, it causes headaches, nausea and eye and respiratory irritations. At higher concentrations $(>200 \mathrm{ppm})$, it can be fatal and can result in death. Figure 5 illustrates hydrogen sulphide plot for main pipe in Sewer Mining scenarios. As can be seen in this figure, the hydrogen sulphide gas has changed after the point of sewage extraction. A drop in hydrogen sulphide gas concentration occurs because hydrogen sulphide was released when wastewater was extracted. However, after the point of extraction, the hydrogen sulphide from Sewer Mining scenarios quickly reform and after a certain pipe length, they exceeded Base Case's hydrogen sulphide concentrations.

On the upstream sewer pipes (before sewage extraction and sludge disposal) the concentration of hydrogen sulphide is similar to that of the Base Case. After sewage extraction some hydrogen sulphide gas concentration decreased due to release of hydrogen sulphide gas to the Sewer Mining treatment plant. The reformation of hydrogen sulphide gas occurred after the location of sewage extraction and sludge disposal; however, hydrogen sulphide gas which exceeded the hydrogen sulphide concentration at Base Case occurred after some pipe distance, depending on sewage volume extraction. Less sewage volume extraction will cause longer distances to exceed the hydrogen sulphide gas concentration at the Base Case, while high sewage extraction will cause shorter distances. The plot of hydrogen sulphide gas concentration at sewer outlet in Figure 6 depicts the impact of Sewer Mining scenarios at the outlet of the Glenroy sewer pipes. Hydrogen sulphide gas concentration in Sewer Mining scenarios was three times higher than the Base Case for SM1, five times higher for SM2 and eight times higher for SM3. This shows that the implementation of Sewer Mining scenarios can contribute to a loss or gain in order to reduce sewer odour of hydrogen sulphide gas, depending on the location of sewage extraction and sludge disposal of the Sewer Mining facility. Sewer Mining can be a strategy to reduce the number of pipes affected by hydrogen sulphide gas; however, it can also be a trigger to exacerbate the impact due to hydrogen sulphide presence. 


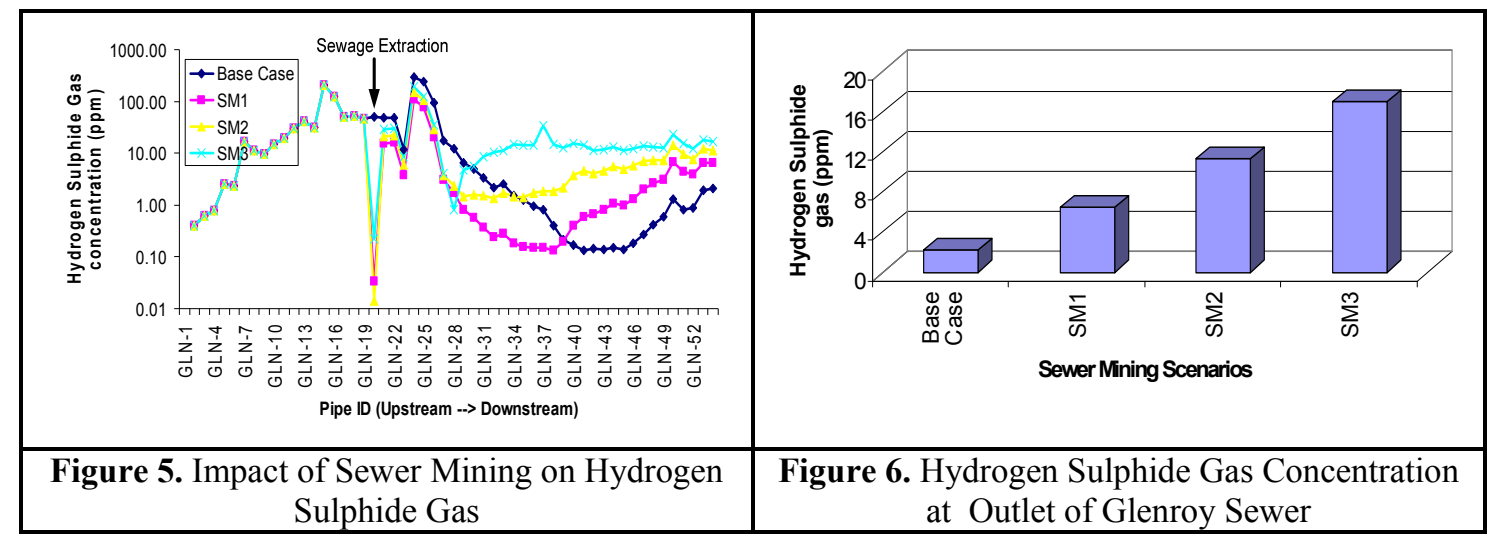

\subsection{Corrosion}

Because of the large capital expenditure each year to correct the effects of hydrogen sulphide corrosion in sewers, it is important to understand the level of corrosion that is likely to occur because of changes in wastewater composition due to the adoption of sewer mining. Pipe corrosion can shorten the life of sewer pipes. The corrosion rate of sewer networks is determined by the pipe material and pipe age. Pipes with high surface reaction i.e. concrete pipe will have high hydrogen sulphide gas adsorption. Most of hydrogen sulphide gas will be adsorbed thus corrosion rate will be high while odour problem will be unlikely to occur (Witherspoon et al. 2004). Further, the corrosion rate will be much faster in aging pipes which typically owned by existing sewer networks. Therefore, existing sewer networks are very much susceptible to corrosion problem. Moreover, it is worsened by the implementation of sewer mining which many of them potential to exacerbate problem of sewer corrosion.

Figure 7 presents the corrosion rate at the outlet of Glenroy sewer. The Base Case has corrosion rate of 0.38 $\mathrm{mm} /$ year, which relatively very small rate. After implementation of SM1; SM2 and SM3, the corrosion rate increase to $0.77 \mathrm{~mm} /$ year; $1.08 \mathrm{~mm} /$ year and $1.39 \mathrm{~mm} /$ year respectively. The least rate increase in SM1 was doubled than the rate in Base Case. It shows that the implementation of Sewer Mining facility can have very deleterious impact on downstream pipes even though the extraction volume is not that high. The corrosion rate in Figure 7 corresponds to the pipe lifetime which is presented in Figure 8. As can be seen in Figure 8, pipe lifetime at the outlet of sewer pipe in Base Case is 400 years. Increase of corrosion rate to $0.77 \mathrm{~mm} / \mathrm{year}$ brought a consequence of reducing the pipe lifetime by 204 years. Shorter lifetime was shown after implementing SM2 and SM3 where it reduces the lifetime by 262 years and 293 year respectively. However, it is important to note that the figures above are only results at the outlet of Glenroy sewer. The other pipes after the point of extraction have varies pipe lifetime even in some pipes that nearby to the point of extraction, the pipe lifetime is longer than the Base Case. This is shown that location of sewage extraction and sludge disposal is very important to determine impact of sewer mining in sewer pipes.

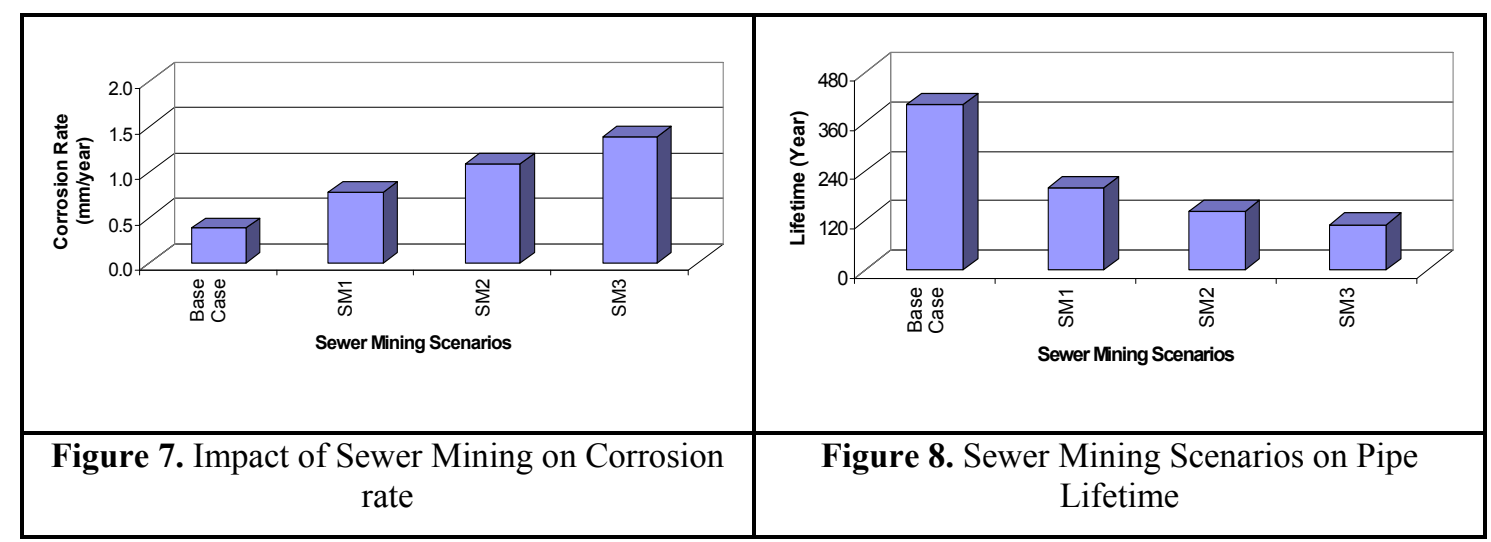




\section{CONCLUSIONS}

Based on this study, the potable water replacement by treated water from sewer mining facility have proved to reduce sewer flow at various levels of reduction, depending on volume of sewage extraction. There are several negative impacts of sewer flow reduction which exacerbates the problem of sewer odour and corrosion by lowering sewer velocity and prolonging sewage residence time as well as increasing the contaminant concentration. The impact of Sewer Mining does not occur immediately after the Sewer Mining point of extraction and sludge disposal point. But the sewer mining facility affects the pipes after some distance downstream of the point of extraction. Impact of Sewer Mining is detrimental to some pipes, but interestingly it also reduces the problem due to a reduction in hydrogen sulphide gas concentration for some pipes immediately downstream of the point of extraction (which consequently increases the pipe lifetime). However, this is dependent on the location of the point of extraction and sludge disposal as well as the volume of sewage extracted. This finding is important, as preventive action of suppressing hydrogen sulphide by chemical dosing can be undertaken for the concerned pipes, where the hydrogen sulphide concentration starts to reach levels detrimental to human health as well as to sewer pipe infrastructure.

\section{ACKNOWLEDGMENTS}

The first author would like to express her gratitude to CSIRO for the Water for Healthy Country Flagship scholarship granted to her for undertaking this research. The authors also thank Yarra Valley Water for providing the data for the case study catchment.

\section{REFERENCES}

Hadzihalilovic, V (2009), Sewer mining for golf course irrigation, Journal of Australia Water Association, 36, 168-71.

Hvitved-Jacobsen, T (2002), Sewer processes: microbial and chemical process engineering of sewer networks, CRC Press.

Hvitved-Jacobsen, T \& Vollertsen, J. (2001), Odour Formation in Sewer Networks, in Stuetz R.M. \& FB Frechen (eds), Odours in Wastewater Treatment : Measurement, Modelling and Control, IWA Publishing.

Jensen, HS, Nielsen, AH, Hvitved-Jacobsen, T \& Vollertsen, J (2009). Modelling of Hydrogen Sulfide Oxidation in Concrete Corrosion Products from Sewer Pipes, Water Environment Research, 81 (4), 365-73.

Marleni, N, Gray, S, Sharma, A, Burn, S \& Muttil, N (2012). Impact of Water Management Practices in Residential Areas on Sewer Network - a review, Water Science \& Technology, 65 (4), 624-42.

McGhie, D, Ventriss, H \& Martin, B (2009). Wastewater Treatment and Sewer Mining in the Swan Valley Area, Western Australia, Science Matters Pty Ltd., Carine.

Nielsen, AH, Vollertsen, J, Jensen, HS, Madsen, HI \& Hvitved-Jacobsen, T (2008), Aerobic and Anaerobic Transformations of Sulfide in a Sewer System Field Study and Model Simulations, Water Environment Research, 80 (1), 16-25.

Nielsen, AH, Yongsiri, C, Hvitved-Jacobsen, T \& Vollertsen, J (2005). Simulation of sulfide buildup in wastewater and atmosphere of sewer networks, Water Science and Technology, 52 (3), 201-208.

Roberts, P (2005). Yarra Valley Water 2004 Residential End Use Measurement Study, Yarra Valley Water, Melbourne.

Sydney Water (2006), Sewer Mining: How to establish a sewer mining operation, Sydney, $<$ http://www.sydneywater.com.au/Publications/FactSheets/SewerMiningHowToEstablishASewerMi ningOperation.pdf $>$.

Sydney Water (2008). Sewer Mining Policy, Program Manager, Recycled Water Market Development.

Tchobanoglous, G, Burton, FL \& Stensel, HD (2003). Wastewater engineering: treatment and reuse, McGraw-Hill Science/Engineering/Math.

Witherspoon, J, Allen, E \& Quigley, C (2004). Modelling to assist in wastewater collection system odour and corrosion potential evaluations. Water Science and Technology, 50 (4), 177-183.

Zhang, LH, De Schryver, P, De Gusseme, B, De Muynck, W, Boon, N \& Verstraete, W (2008), Chemical and biological technologies for hydrogen sulfide emission control in sewer systems: a review, Water Research, 42 (1-2), 1-12. 